\title{
Mid-Tropospheric Cyclones of the Southwest Monsoon
}

\author{
T. N. KRISHNAMURTI \\ Dept. of Meleorology, Florida State University, Tallahassee \\ aND R. S. HaWkINS \\ Air Force Cambridge Research Laboratories, Bedford, Mass. \\ (Manuscript received 17 November 1969, in revised form 12 February 1970)
}

\begin{abstract}
Mid-tropospheric cyciones are an important part of the tropical general circulation of the summer season. These are synoptic-scale disturbances which appear in the daily and monthly mean circulation maps with greatest intensity at levels near $500 \mathrm{mb}$. The structure and energetics of this type over southeast Asia are discussed in this paper. Interesting features include a warm anomaly above the cyclone and a cold anomaly below.

A five-level non-geostrophic balanced model is used in this study to obtain the distribution of vertical motion. The model includes a parameterization of cumulus-scale convection. In the middle levels, rising motions are found west of the cyclone and sinking motions to the east. This is primarily due to the thermal structure of the atmosphere and associated advection of colder air from the oceanic regions and warmer air from land areas. A marked diurnal change in the vertical velocity is noted in the computations; magnitudes are large at 0700 local time compared to 1900 . This diurnal change is primarily due to changes in the wind direction and speed. The important result of this study is that both the cumulus- and synoptic-scale motions exhibit the following dual roles in the maintenance of this midlevel system:

1) Both scales contribute to a net warming of the air above the cyclone, diabatic warming by cumulus-scale motions and adiabatic warming by the descent of synoptic-scale motions.

2) The two scales oppose each other in the transformation eddy available potential energy into eddy kinetic energy. Cumulus-scale motions contribute to a net generation, while synoptic-scale motions transform kinetic energy into potential energy. This latter result is consistent with 1) because the areas of descent are somewhat closer to the warm temperature anomaly than are the areas of ascent.
\end{abstract}

\section{Mid-level cyclones as a feature of monthly mean circulations}

During the summer southwest monsoon season, several quasi-stationary mid-tropospheric cyclones (wavelength $\sim 1000 \mathrm{~km}$ ) are observed over southeast Asia. These cyclones are frequently found north of the Bay of Bengal, over the northeastern part of the Arabian Sea and over southern Indochina. References to these

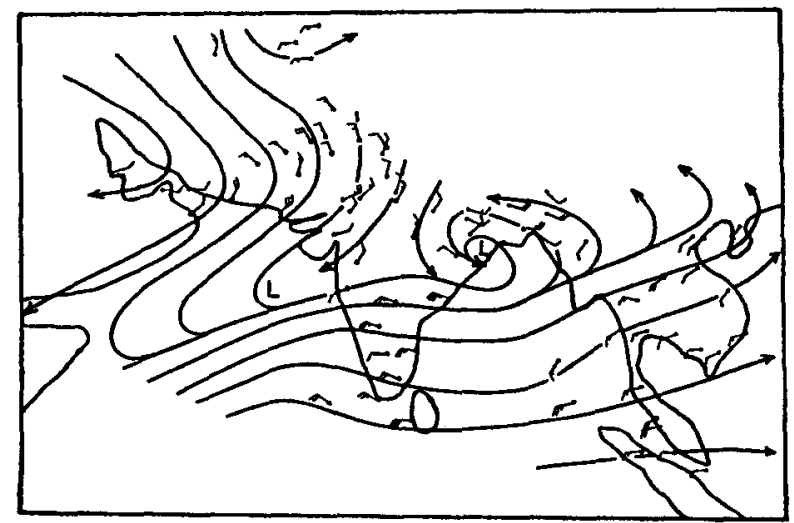

Fig. 1. Normal map for July at $4 \mathrm{~km}$. [From C. W. B. Normand's Climalological A tlas for Airmen (1943)]. are found in the works of Miller and Keshavamurthy (1967) and Sadler (1968).

Fig. 1 is a normal map from the Climatological Atlas for Airmen prepared by C. W. B. Normand (1943). It is a mean map based on more than 10 years of data for July at the $4 \mathrm{~km}$ level. The mean streamlines rather clearly demonstrate the existence of a mid-level cyclonic circulation over the northwestern part of the Bay of Bengal. A cyclonic trough is found over the northeastern part of the Arabian Sea.

On the larger scale, there is no clear evidence of an organized cyclonic circulation in the middle levels over southern Indochina. July mean maps prepared by Miller and Keshavamurthy, based on the International Indian Ocean Expedition data, show the presence of these middle-level cyclones. There is also some evidence of a mid-level cyclone over southern Indochina in the recent mean maps for July by Sadler. It is, however, not as clearly defined as those found over the Arabian Sea and the Bay of Bengal. Fig. 2 is a monthly mean map for July at the 500-mb surface based on the above-mentioned references. The heavy dashed line connects the three major mid-level cyclones of the southwest monsoon. Solid lines are streamlines and thin dashed lines are isotachs of the monthly mean wind speed field. 


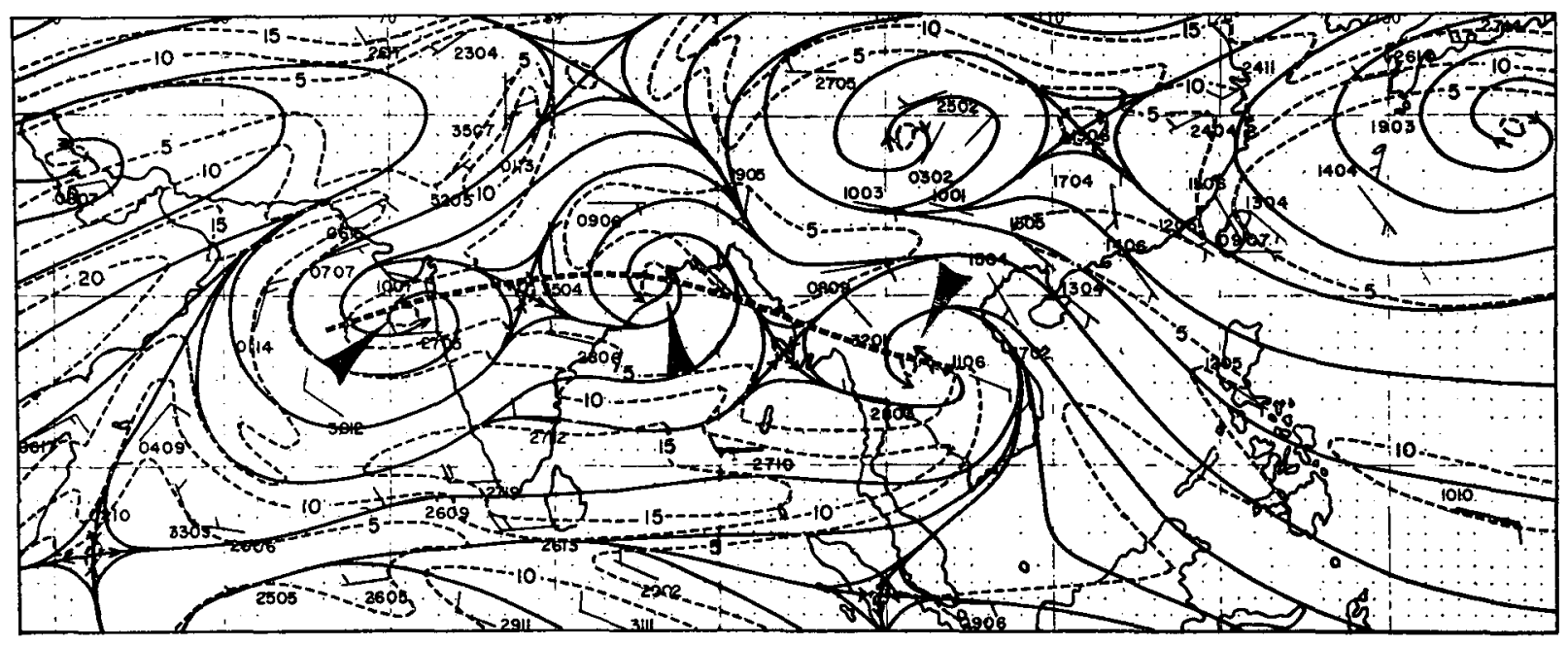

FIG. 2. July mean map, at $500 \mathrm{mb}$, based on more recent data, showing the location of mid-level cyclones.

\section{The problem}

In an intense mid-level cyclone $(\zeta>0), \partial \zeta / \partial p>0$ above the level of maximum intensity and $\partial \zeta / \partial p<0$ below ${ }^{1}$. Throughout an appreciable depth, $\partial^{2} \zeta / \partial p^{2}<0$. A consequence of such a vertical distribution of $\zeta$ is that a warm temperature anomaly $T^{\prime}$ will be found above such a cyclone and a cold anomaly will be observed below the cyclone. This type of structure, as illustrated by Fig. 3, can be viewed in terms of hydrostatic balance or from the thermal wind relationship.

Figs. 3a-c show a schematic diagram of the typical pressure distribution over southeast Asia during summer months. A vertical cross section along lines $A B$, intersecting the mid-level cyclone (Fig. 3b), is illustrated in Fig. 3d. In going from point $A$ to $B$, a decrease in geopotential height is observed at $900 \mathrm{mb}$, an increase is observed at $200 \mathrm{mb}$, and at $500 \mathrm{mb}$ the mid-level cyclone is intersected. The warm anomaly above and cold anomaly below the middle-level cyclone are clearly illustrated in this figure.

The question as to how the vorticity of the mid-level cyclone is maintained is therefore intimately related to the question of the maintenance of the vertical distribution of these temperature anomalies. In this paper we shall present results of computations of threedimensional vertical motions based on a nonlinear balanced model (including effects of terrain, cumulusscale heating, and parameterized air-sea interactions). By constructing backward trajectories (passing through the mid-level cyclone), an attempt will be made to determine mechanisms which maintain the observed temperature anomalies. It is hoped that this preliminary study will eventually lead to a formulation of a prediction model and achieve a better understanding of this phenomenon.

Charney (1969) and Yanai et al. (1968) have recently

\footnotetext{
${ }^{1}$ See the Appendix for a list of symbols and their definitions.
}

stressed the importance of a lack of coupling of lowerand upper-level systems in the tropics. Several earlier investigators, including Riehl (1954), also pointed out that most of the eddy motions in the tropics are in the lower and upper troposphere. In this study, however, the observations show that synoptic-scale cyclones are present in both individual and monthly mean maps at

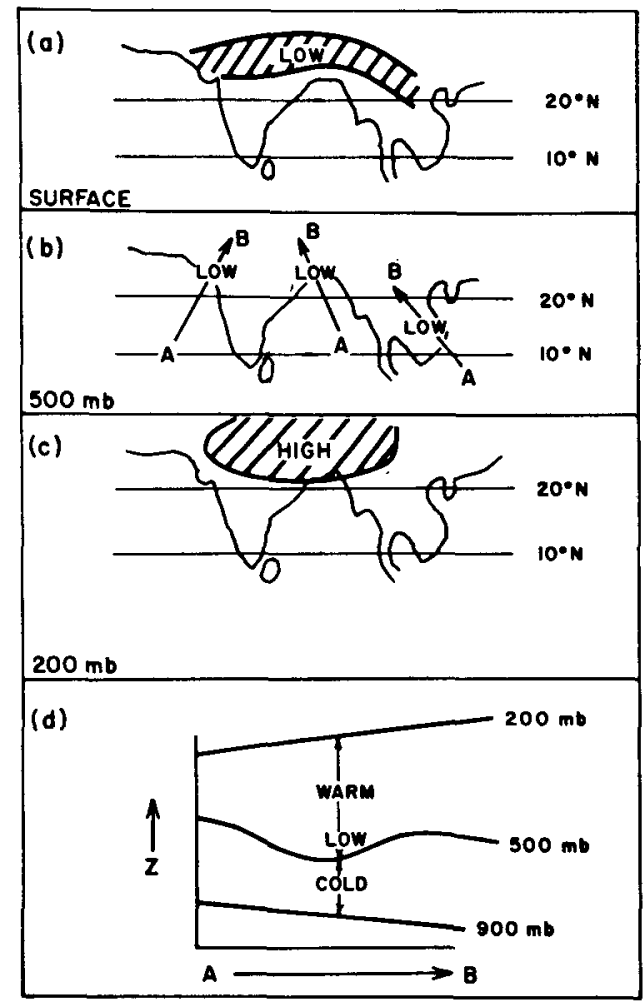

FIg. 3. Schematic diagram showing pressure distributions at the lower, middle and upper troposphere (a)-(c). The bottom drawing shows the slopes of the $900-, 500$ - and $200-\mathrm{mb}$ surfaces and the temperature anomalies in a vertical cross section. 
middle levels. A large part of the eddy kinetic energy at middle levels in this region is in association with cyclonic systems which are a part of the summer monsoon complex of southeast Asia. There are large zonal asymmetries in the tropics, and mid-level features over the oceanic regions are quite different than observed over southeast Asia. Furthermore, seasonal differences in scales of motions are also quite large in the tropics. These are intriguing features which make the tropics a complicated and challenging area for large-scale meteorological research.

\section{On the computations of vertical velocity}

The procedure used for computation of vertical velocity $\omega$ is similar to that described in Krishnamurti (1968a). In order to obtain a three-dimensional distribution of $\omega$, the following fields are required at several levels: streamlines, isotachs, isotherms, relative humidity, ocean temperatures (monthly means), and terrain heights. The model contains the influence of air-sea interactions, terrain upslope and downslope motions, cumulus-scale heating, and several other features. A $1^{\circ}$ latitude by $1^{\circ}$ longitude mesh on a Mercator map projection was used for computations. While the model is internally consistent, the most serious drawback is the lack of data on the mesoscale. As a result, some of the details may not be quite representative on the smaller scale.

The non-divergent part of the wind, $V_{\psi}$, is obtained from a solution of

$$
\begin{gathered}
\nabla^{2} \psi=\zeta, \\
\mathbf{V}_{\psi}=\mathbf{k} \times \nabla \psi,
\end{gathered}
$$

where $\zeta$ is the relative vorticity of the observed wind. Boundary conditions for $\psi$ are obtained by the procedure outlined by Hawkins and Rosenthal (1965) using method 2. of their work. This particular choice of boundary condition permits no net mass flux from the domain; however, $\psi$ varies along the boundaries.

The following other equations are used in the present study:

\section{Omega equation}

$$
\begin{gathered}
\nabla^{2} \sigma \omega+f^{2} \frac{\partial^{2} \omega}{\partial p^{2}}=f \frac{\partial}{\partial p} J\left(\psi, \zeta_{a}\right)+\pi \nabla^{2} J(\psi, \theta) \\
+f \frac{\partial}{\partial p} g \frac{\partial}{\partial p}\left(\frac{\partial \tau_{y}}{\partial x}-\frac{\partial \tau_{x}}{\partial y}\right)-2 \frac{\partial}{\partial t} \frac{\partial}{\partial p} J\left(\frac{\partial \psi}{\partial x}, \frac{\partial \psi}{\partial y}\right) \\
-f \frac{\partial}{\partial p}\left(\zeta \nabla^{2} X\right)-\frac{R}{C_{p} p} \nabla^{2} H+f \frac{\partial}{\partial p}\left(\omega \frac{\partial}{\partial p} \nabla^{2} \psi\right) \\
+f \frac{\partial}{\partial p}\left(\nabla \omega \cdot \nabla \frac{\partial \psi}{\partial p}\right)-f \frac{\partial}{\partial p}\left(\nabla \chi \cdot \nabla \zeta_{a}\right) \\
-\pi \nabla^{2}(\nabla \chi \cdot \nabla \theta)-\beta \frac{\partial}{\partial p} \frac{\partial}{\partial y} \frac{\partial \Psi}{\partial t} .
\end{gathered}
$$

\section{Continuity equation}

$$
\nabla^{2} \chi=\frac{\partial \omega}{\partial p}
$$

Vorticity equation

$$
\begin{aligned}
\nabla^{2} \frac{\partial \psi}{\partial t}=-J\left(\psi, \zeta_{a}\right)+ & \nabla \chi \cdot \nabla \zeta_{a}+\zeta_{a} \nabla^{2} \chi-\omega \frac{\partial}{\partial p} \nabla^{2} \psi \\
& -\nabla \omega \cdot \nabla \frac{\partial \psi}{\partial p}-g \frac{\partial}{\partial p}\left(\frac{\partial \tau_{y}}{\partial x}-\frac{\partial \tau_{x}}{\partial y}\right) .
\end{aligned}
$$

The boundary conditions are as follows:

$$
\text { At } p=100 \mathrm{mb}, \omega=0
$$

At the southern wall, $y=y_{1}, \omega=\chi=\frac{\partial \psi}{\partial t}=0$;

At the northern wall, $y=y_{2}, \omega=\chi=\frac{\partial \psi}{\partial t}=0$;

$$
\text { At } p=1000 \mathrm{mb}, \omega=-g\left(\frac{1000}{R \theta_{0}}\right)[J(\psi, h)-\nabla \chi \cdot \nabla h] \text {. }
$$

The solutions for $\omega, \chi$ and $\partial \psi / \partial t$ are obtained by a successive approximation procedure. This involves three-dimensional relaxation for $\omega$ and two-dimensional relaxation for $\chi$ and $\partial \psi / \partial t$. These three equations are coupled.

In this diagnostic model diabatic heating rate per unit mass of air is split into the two components

$$
H=H_{S}+H_{L},
$$

where $H_{S}$ is the transfer of sensible heat from the ocean and $H_{L}$ the release of latent heat. Radiative effects have not been included.

The sensible heat at the $900-\mathrm{mb}$ surface is expressed by (see Krishnamurti, 1968a)

$$
H_{S}=0.00323 V\left(T_{w}-T_{a}\right),
$$

where $H_{S}$ is in $\mathrm{m}^{2} \mathrm{sec}^{-3}, V$ the wind speed in $\mathrm{m} \mathrm{sec}^{-1}$ at anemometer level and $\left(T_{w}-T_{a}\right)$ the difference $\left({ }^{\circ} \mathrm{C}\right)$ between the water temperature and the air temperature at anemometer level.

The procedure for parameterization of the cumulus scale as a function of the large-scale motion, with the mutual modification of the two scales, is carried out using the approach used by Kuo (1965) for a tropical storm.

Heat is released if the following criteria are met: 1) $-\partial \theta e / \partial p<0$ at any level above $1000 \mathrm{mb}$. This measures the moist conditional instability. 2) Net moisture convergence $>0$ in vertical columns which extend from the top of the friction layer to the top of atmosphere (100 mb). 
The heating function, $H_{L}$, is defined by

$$
H_{L}=C_{p} \frac{a}{\Delta t}\left(T_{c}-T\right)
$$

where $\left(T_{\mathrm{c}}-T\right)$ is the temperature difference between cloud element and tropical environment, $C_{p}$ the specific heat of air at constant pressure, $\Delta t$ a cloud timescale, and $a$ the fraction of area covered by convective clouds.

Surface frictional stresses $\tau_{x}$ and $\tau_{y}$ are defined in terms of a surface roughness constant applied at the lower level, $p=1000 \mathrm{mb}$.

\section{Mid-level cyclone over southern Indochina}

A few selected maps for June 1966 will be presented from the large number of cases prepared during this investigation. Maps at the surface, $500-$ and $200-\mathrm{mb}$ levels are shown in Figs. 4a-d for four map times over the period 16-18 June. In all, six case studies over this region were prepared.

\section{a. Surface winds}

Because of orography, the analyzed features are only representative of surface flows over oceans and the central plains of Cambodia. At $10 \mathrm{~N}$ there is a marked diurnal change in surface winds between 1200 GMT (westerly) and 0000 GMT (southerly). Time continuity is not very clear in the surface wind field. Flow is fairly typical of the southwest monsoon. The monsoon low pressure trough is located around $17-22 \mathrm{~N}$. The circulation around the heat low is more organized at 1200 GMT (1900 local time) than at 0000.

\section{b. $500 \mathrm{mb}$}

The mid-level cyclone is located near $10 \mathrm{~N}$ and moves slowly westward during the four map times. A warm temperature feature ( $-2 \mathrm{C}, 16$ June, 1200 GMT) gradually moves westward, isotherms being shown as dashed lines (interval, 1C). Marked intersection of streamlines and isotherms clearly indicates regions of cold advection east of the mid-level cyclone and warm advection west of the cyclone. This turns out to be an important aspect of the mid-level cyclones, although advective effects are usually considered small in the tropics. Exceptions to this may be found in the vicinity of hurricanes, monsoon circulations, and tropical coldlows over oceanic areas. However, temperature gradients are not always negligible in the tropics (see Erickson, 1969), and whenever temperature gradients $\gtrsim 1 \mathrm{C}(300 \mathrm{~km})^{-1}$ are found there are important synopticscale regions of rising and sinking motions, primarily resulting from warm and cold horizontal advection. This does not, however, lead to the inference that in these disturbances there is a net ascent of warm air and a descent of cold air. On the contrary, we find that maximum cold advection occurs closer to the axis of warmest temperature anomaly and maximum warm advection occurs some distance away from the warm anomaly. The implication of this to the energetics will be discussed later.

\section{c. $200 \mathrm{mb}$}

The mid-level cyclone of Indochina lies southeast of the upper tropospheric position of the large upper anticyclone of the summer season. Winds at the $200-\mathrm{mb}$ level over the mid-level cyclone are very steady with easterlies around 20-40 kt increasing steadily westward. The net convergence at $200 \mathrm{mb}$ is consistent with a gradual descending motion on the planetary scale and this is confirmed by our dynamical calculations. Temperature increases gradually westward over this region with the warmest air near the Tibetan plateau. No local warm or cold temperature anomalies are observed at this level.

\section{Mid-level cyclones over India}

Results of computations of dynamical parameters over southern Indochina have been compared with those obtained from mid-level cyclones over India. Computations have been made for a case presented by Miller and Keshavamurthy (1967) for which considerable detail could be provided by the Indian Ocean expedition aircraft data. The case selected, 7 July 1963, 1200 GMT, has an intense mid-level cyclone present over the northeastern Arabian Sea and a weaker system over the northern Bay of Bengal. The locations of these cyclones, at $\sim 20 \mathrm{~N}$, are shown at the $500-\mathrm{mb}$ level in Fig. 5. At $200 \mathrm{mb}$ (Fig. 6) the flow is from the east with a weak easterly jet. Observed circulation patterns at other levels are shown in Miller and Keshavamurthy.

\section{Vertical structure of mid-level cyclones}

Figs. $7 \mathrm{a}-\mathrm{c}$ are three examples of west-to-east vertical cross sections made through the mid-level cyclones presented in Figs. 4a-d; Figs. 7a and $\mathrm{b}$ have been taken at $10 \mathrm{~N}$ through the cyclones over southern Indochina shown in Fig. 4, while the cross section in $7 \mathrm{c}$ is at $20 \mathrm{~N}$ through the cyclones over India shown in Fig. 5. The center of the cyclone is well marked in each case by a maximum in the absolute vorticity field. The cross sections also contain the distributions of temperature $T^{\prime}$ and vertical velocity $\omega$. Values of $\zeta_{a}$ in the mid-level cyclones were as high as $80 \times 10^{-6} \mathrm{sec}^{-1}$. This "trapped" mid-level vorticity is a puzzling phenomenon of the Asian southwest monsoon circulations. Above the center of the maximum vorticity, a warm anomaly is found in each of these cross sections. The intensity of the warm anomaly is greater over India than over southern Indochina. Rising motions are found to the west of the cyclone and sinking motions to the east. The rising air has a northerly component with associ- 

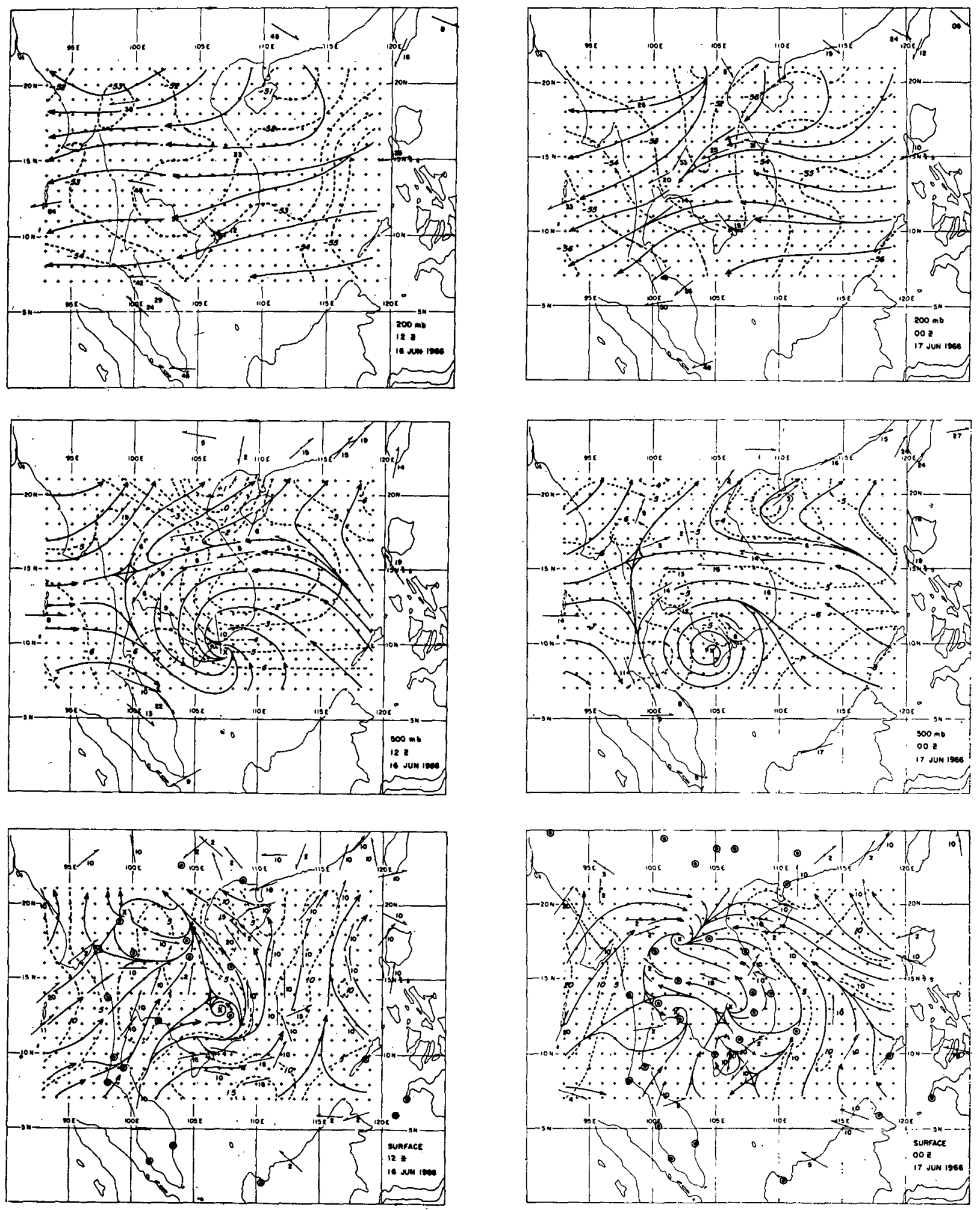

FIG. 4. Streamlines and isotherms at the surface and 500 and $200 \mathrm{mb}$ for 12 -hr intervals from 1200 GMT 16 June 1966 to 0000 GMT 18 June 1966. 

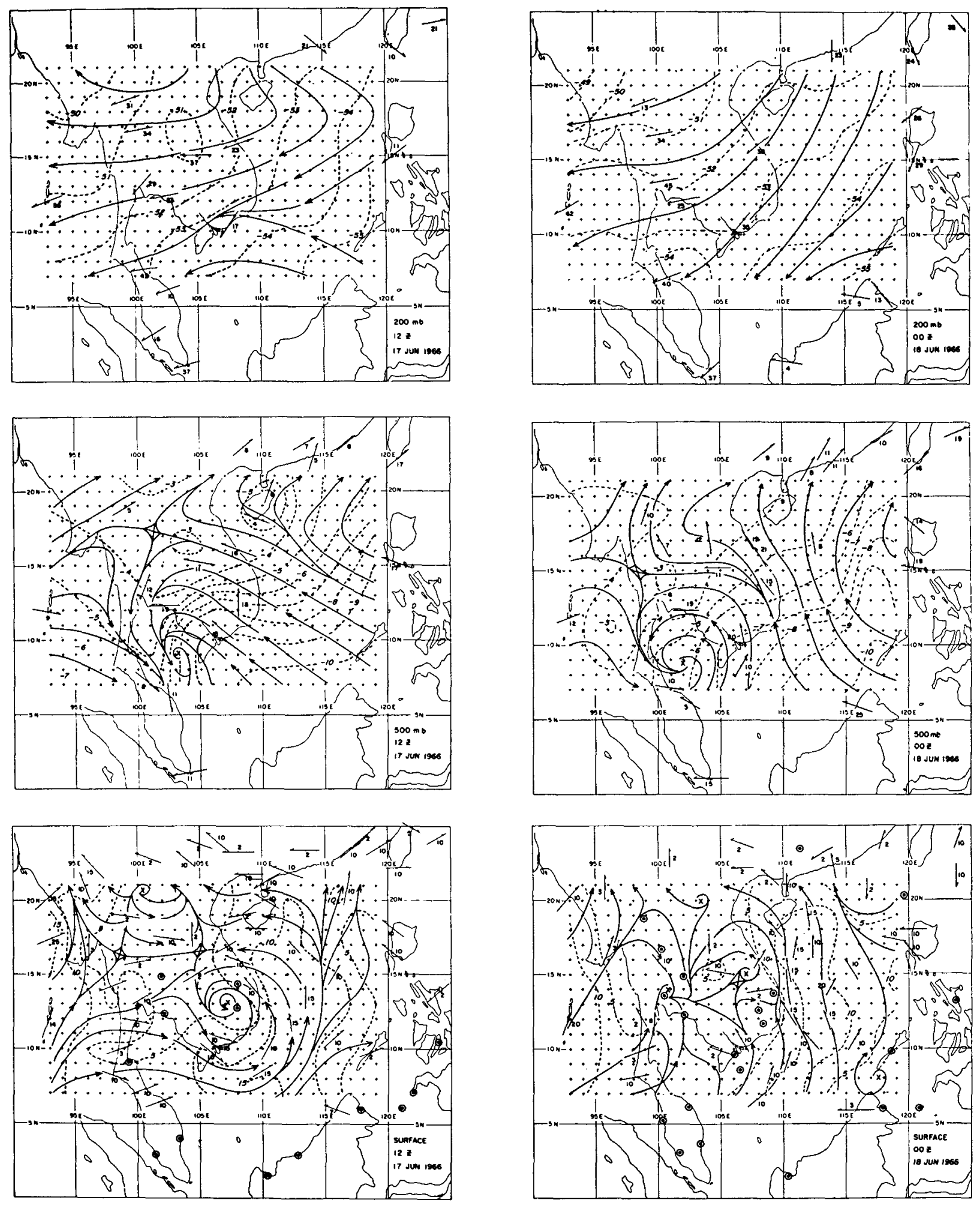

FIG. 4 (continued). 


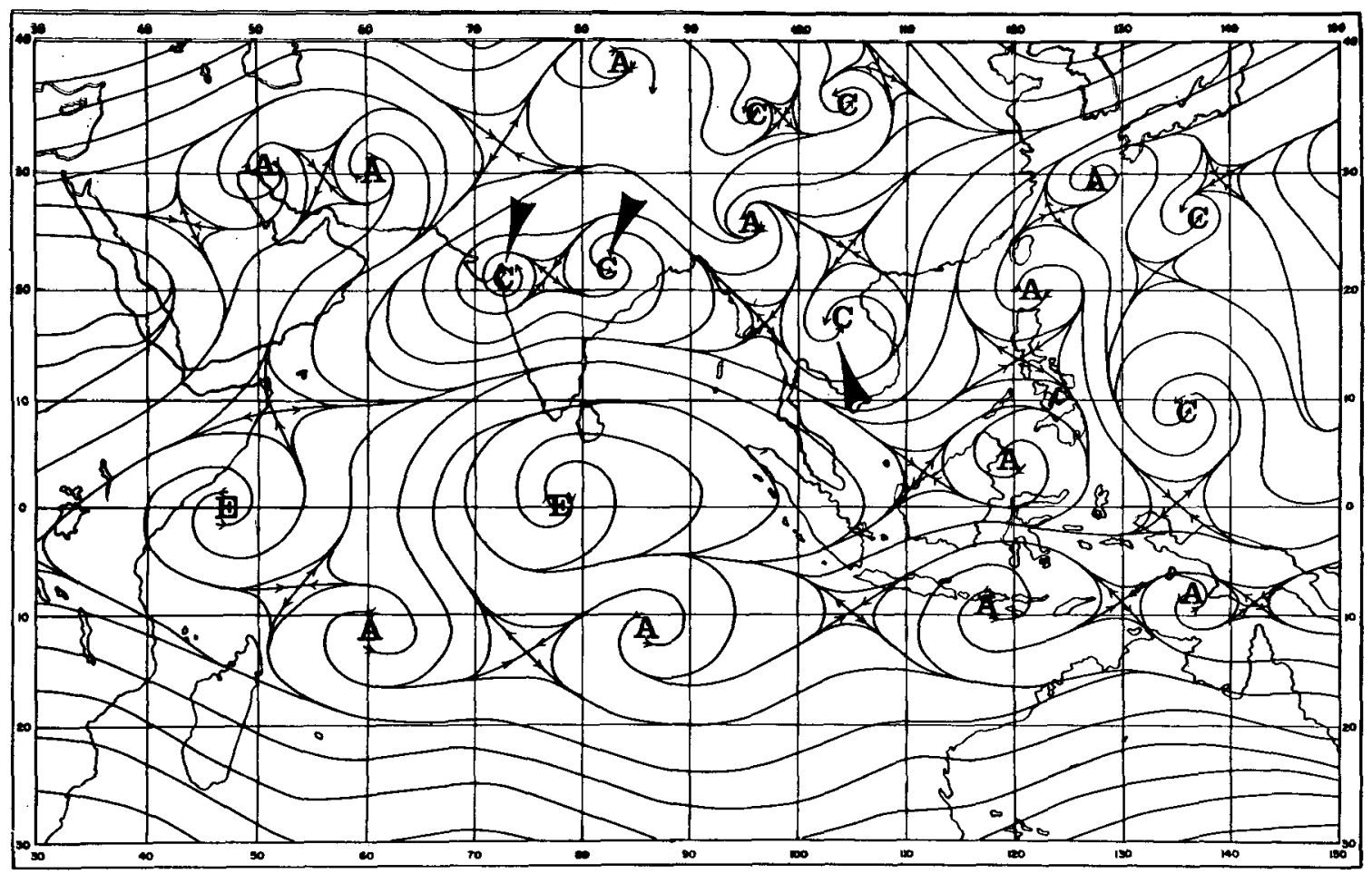

FIG. 5. Streamlines at $500 \mathrm{mb}$ at 1200 GMT 7 July 1963.

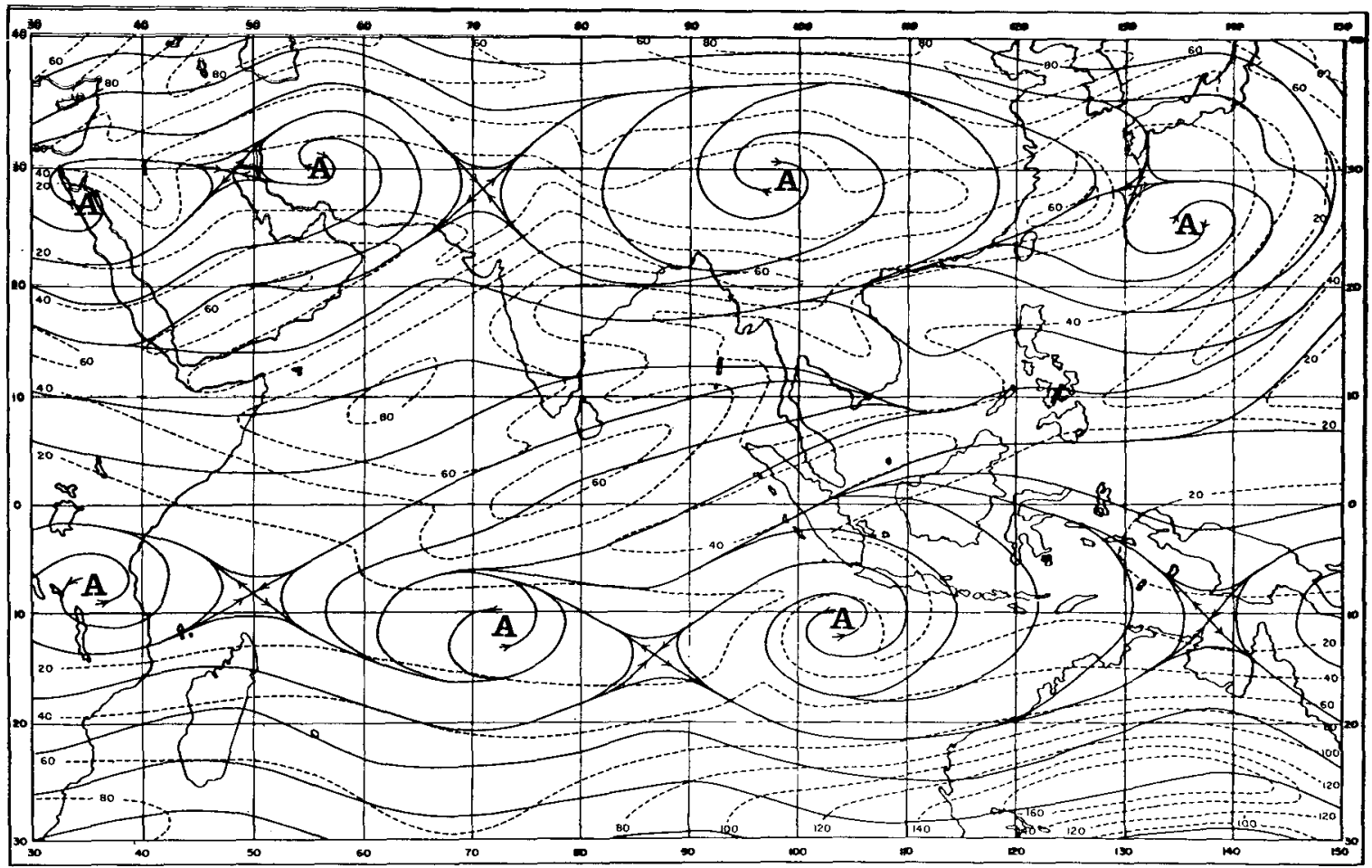

FIG. 6. Streamlines at $200 \mathrm{mb}$ at $1200 \mathrm{GMT} 7$ July 1963. 

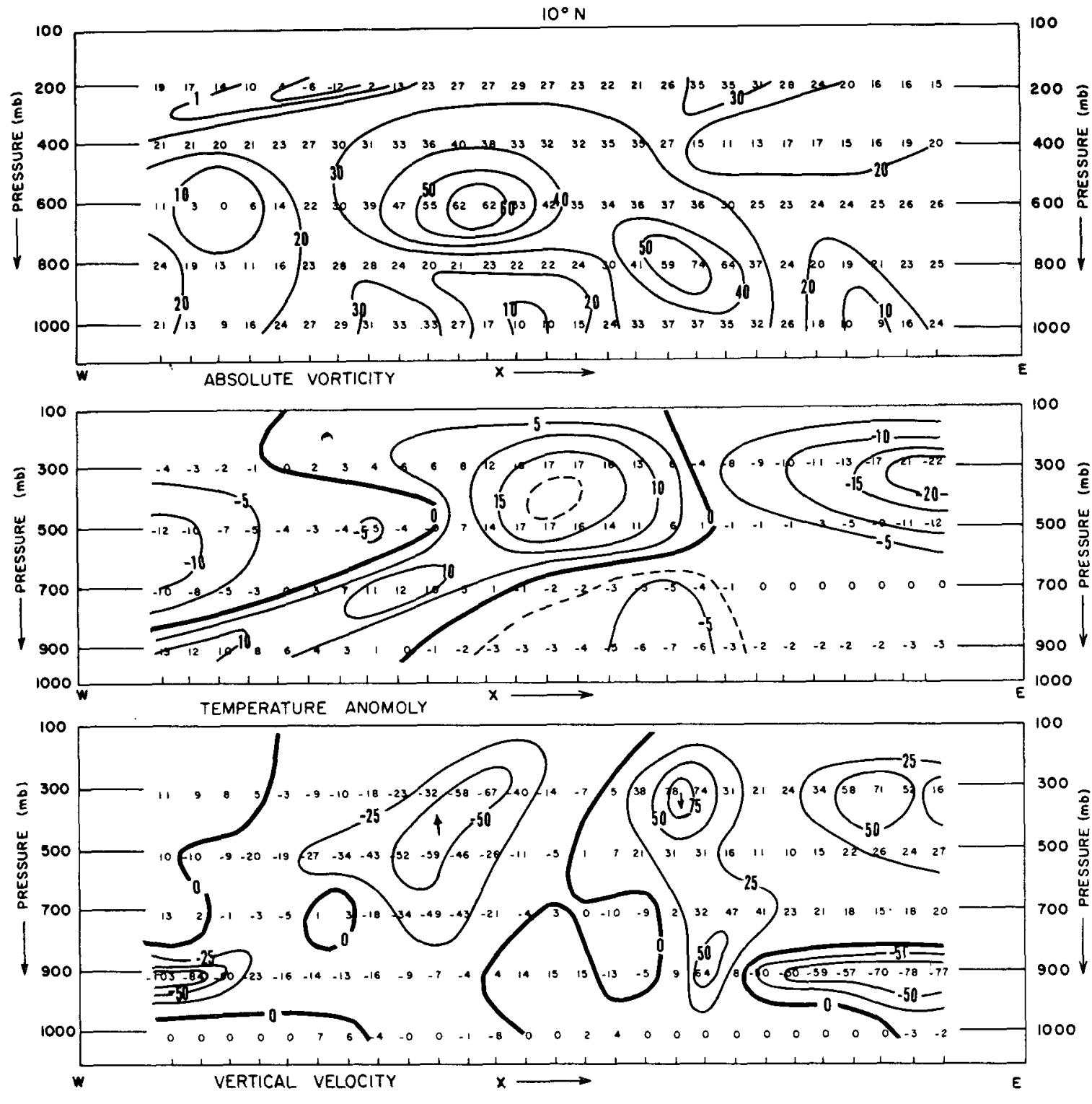

5000 FEET

4000

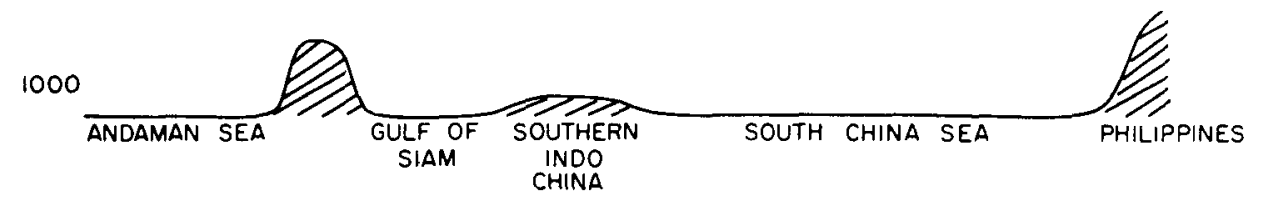

FIG. 7a. Vertical cross section from west to east at 10N for 0000 GMT 17 June 1966 through the mid-level cyclone over southern Indochina. Top: isopleths of absolute vorticity $\left(10^{-5} \mathrm{sec}^{-1}\right)$; middle: isopleths of temperature anomaly $\left(10^{-1} \mathrm{C}\right)$; bottom: isopleths of vertical velocity $\left(10^{-5} \mathrm{mb} \mathrm{sec}^{-1}\right)$. A profile of the smoothed terrain is indicated at the bottom of the cross sections.

ated advection of warm and dry air. In some portions of the cross sections the boundary layer convergence is large, and maxima in the vertical velocity are found near $900 \mathrm{mb}$. The vertical motion of the upper level systems appears to couple and uncouple with the lower level rising and sinking motion distributions. These zonal cross sections show a vertical tilt of the vorticity maxima toward the west. In the north-south plane (cross sections) the vorticity maxima have a southward tilt with height, with the tilt toward colder 

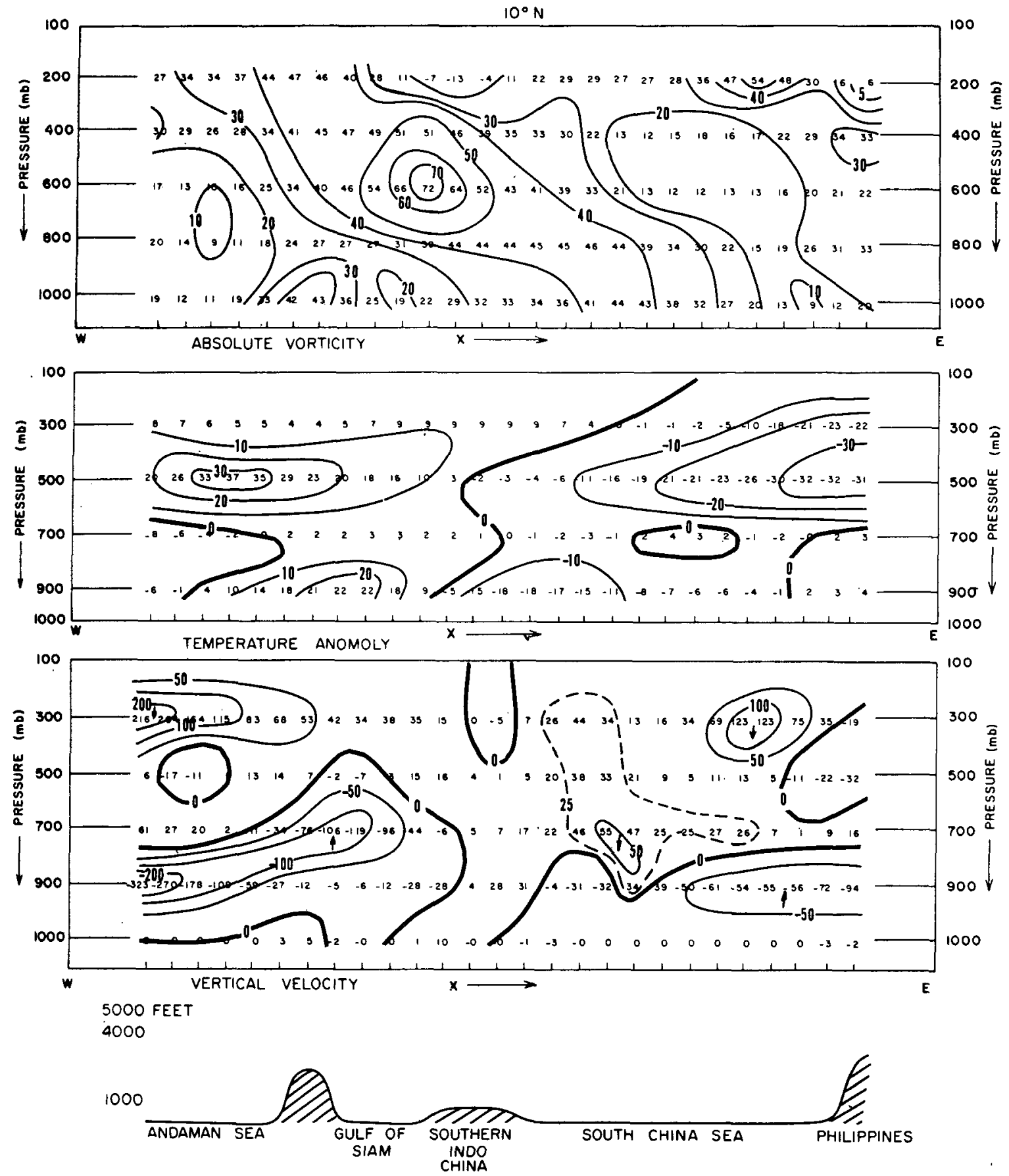

Fig. 7b. Same as Fig. 7a except for 0000 GMT 18 June 1966.

air. The greatest tilt is found near the surface and in the upper troposphere.

The cross sections show that the warmest temperature anomaly is near the location where the upper easterlies change their sign of vertical motion. This was found to be the case in almost all of the examples that were investigated. This is an observational evidence of the role of subsidence warming in the maintenance of the warm anomaly.

\section{Horizontal distribution of vertical motion}

The nonlinear balanced model used in the present study resolves vertical velocity into a number of com- 

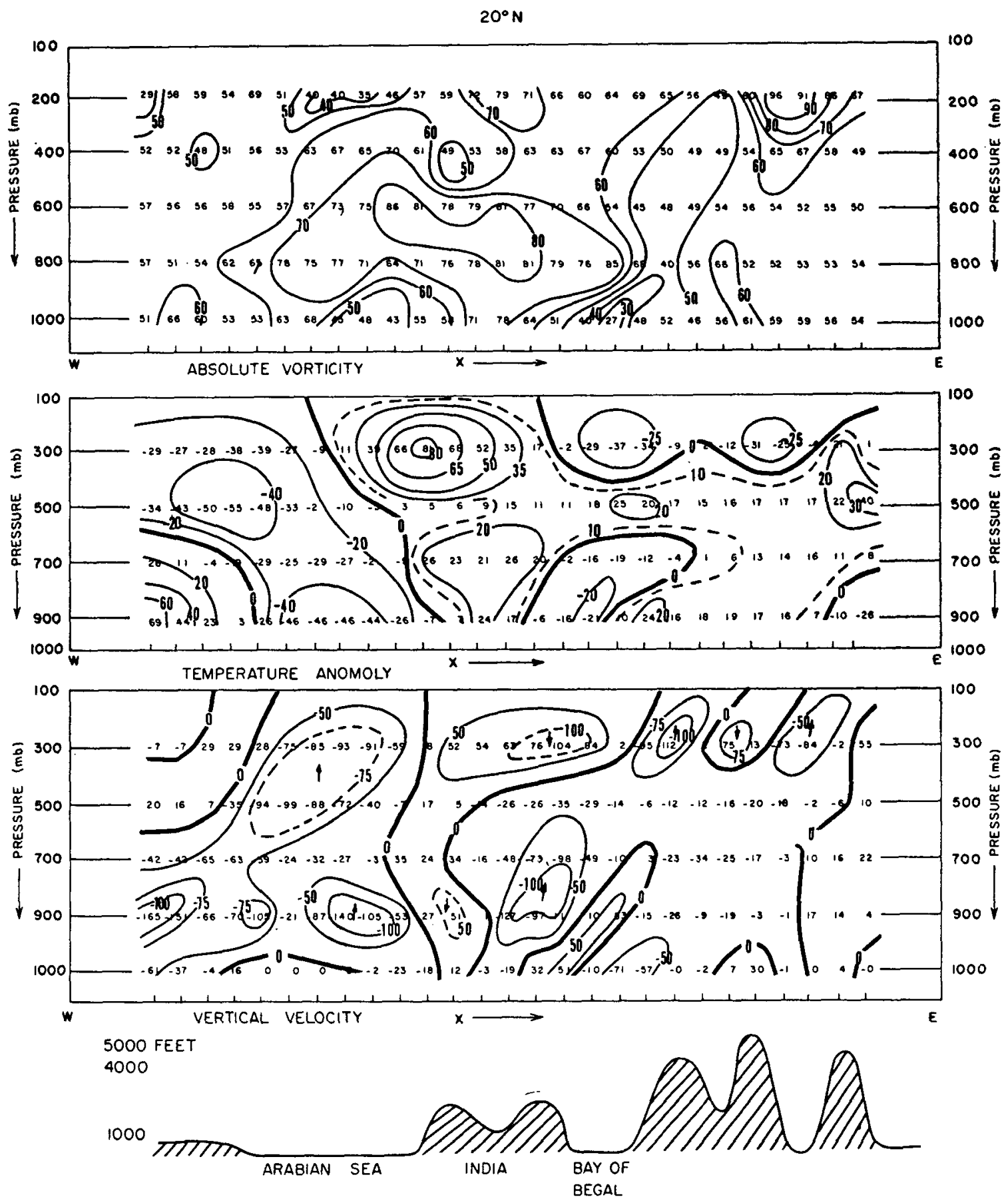

Fig. 7c. Same as Fig. 7a except for 1200 GMT 7 July 1963 at $20 \mathrm{~N}$ for the mid-Ievel cyclone over India and southeast Asia.

ponents (Krishnamurti, 1968a). An examination of the details of the vertical motion revealed that thermal advection was a primary contributor to the total vertical motion in the vicinity of the mid-level cyclone. This is not surprising in view of the thermal structure of the disturbance and its relation to the motion field. Air over the oceanic regions is cooler than that over land and strong thermal advection is observed in some regions. Flow from the land areas is associated with warm advection and rising motions, with the converse being true for flow from the oceanic areas. Fig. 8 shows the horizontal distribution of vertical motion at $700 \mathrm{mb}$ 

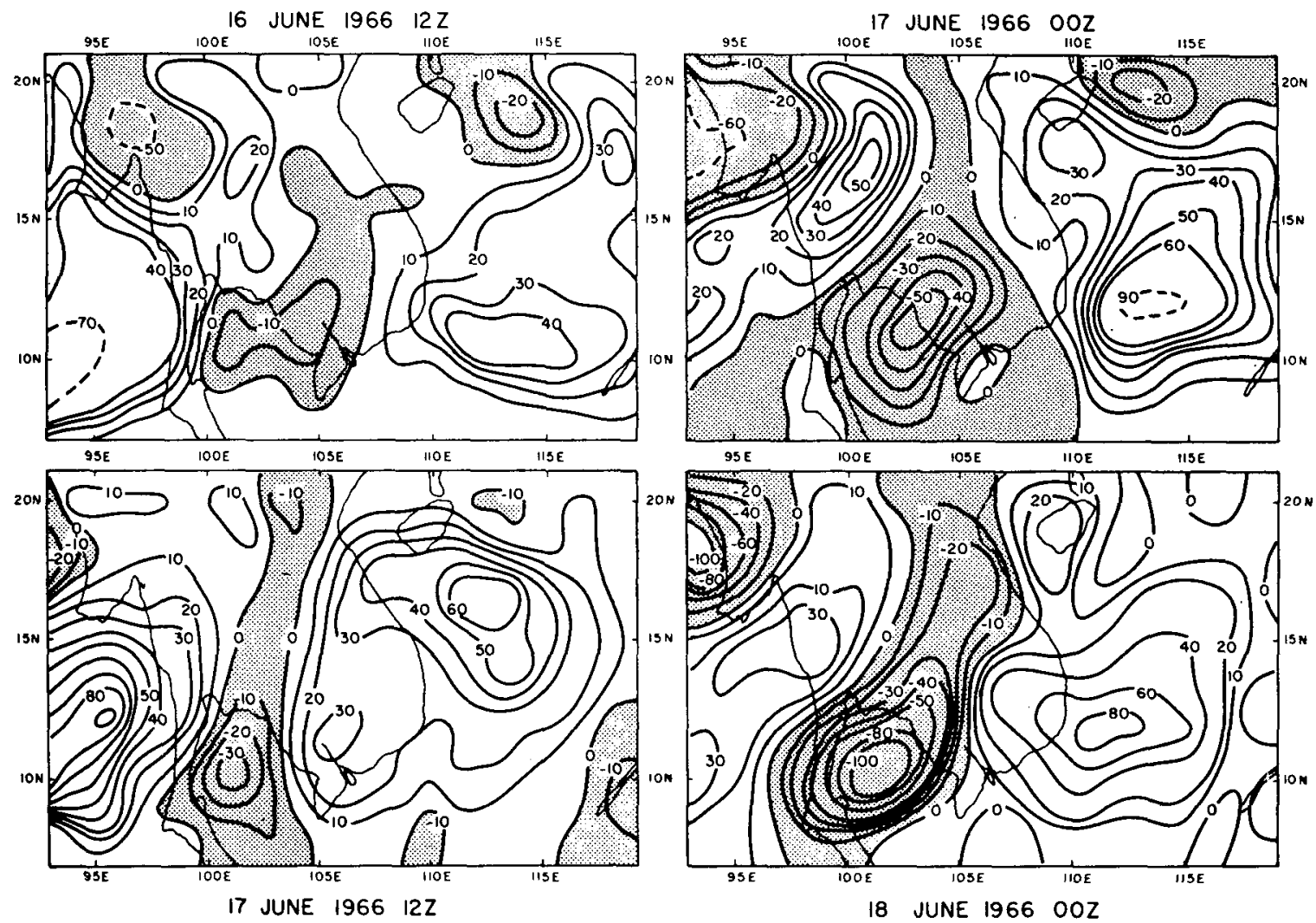

FIG. 8. Horizontal distribution of vertical motion $\left(10^{-5} \mathrm{mb} \mathrm{sec}^{-1}\right)$ for four map times at $700 \mathrm{mb}$. Shaded areas indicate ascending motion.

for four map times over southern Indochina. Largest magnitudes of vertical velocity are of the order of $1 \mathrm{~cm}$ $\mathrm{sec}^{-1}$, but these appear to have physical importance since the regions of rising motions correlate reasonably well with the cloud cover during these periods (Fig. 9). We are also extending these studies over larger areas including southeast Asia and India. The results of these studies will be reported later.

\section{Diurnal changes in vertical velocity}

Remarkable diurnal differences in the magnitude of lower tropospheric vertical velocity $\omega$ were noted in the computed fields. The magnitudes $|\omega|$ were systematically lower at $1200 \mathrm{GMT}$ (1900 local time) as compared to 0000 GMT (0700 local time). A further examination of the distribution of the dependent variables (Fig. 4) revealed that this diurnal change in $|\omega|$ was primarily due to a systematic change in the distribution of wind vectors and not in the thermal field or its gradients. The primary forcing function in the $\omega$ equation in the vicinity of the mid-level cyclone is the Laplacian of thermal advection. Its magnitude is reduced during afternoon hours and increased during nighttime due to the changes in the wind speed and direction. These results are in accordance with recent findings of Kreitzberg (1969) who used a mesoscale network of $\sim 20$ aerological stations over southern Indochina. $\mathrm{He}$ found marked diurnal changes in the vertical distribution of moisture which he attributed to diurnal changes in the vertical motion field.

Other features of interest found by K reitzberg include a low-level mesoscale speed maxima of the order of $40 \mathrm{kt}$ and lateral dimensions $<1^{\circ}$ latitude. $\mathrm{He}$ found that regions with active cumulus convection were located roughly over the regions of maximum low-level cyclonic relative vorticity. This is a confirmation of the presence of an Ekman-type boundary layer over land areas where the coupling between cumulus-scale and the low-level mass convergence seems to be on the mesoscale. Charney (1968) has proposed similar ideas in his theory of the intertropical convergence zone. Fujita et al. (1969) have used cloud motions from synchronous ATS satellites to show, over oceanic regions of the tropics, that the low-level wind does exhibit a relative cyclonic vorticity maxima on the mesoscale below organized 


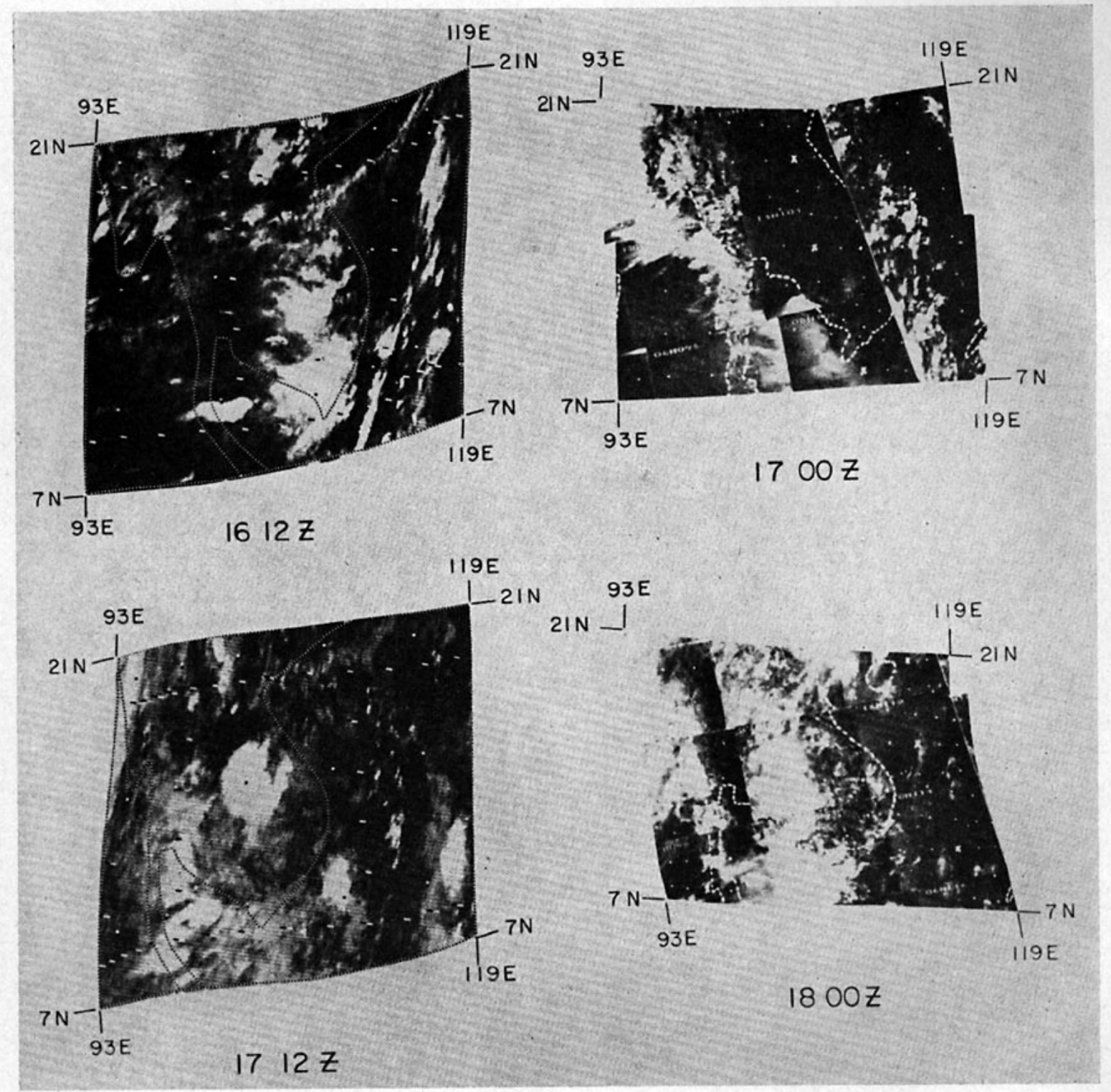

FIG. 9. Satellite cloud photographs showing cloud cover at approximately the map time under investigation (Fig. 4).

bands of cumulus convection. It is remarkable that over land areas similar structures were noted by Kreitzberg.

Lack of mesoscale data makes it very difficult to parameterize cumulus convection properly. An attempt has been made to take this effect into account in a rather rough manner. In general, for larger scale numerical prediction in the tropics, it would be impossible to expect mesoscale data over the entire regions. However, theoretical work on the formation of mesoscale velocity streaks in the boundary layer of a conditionally stable air mass may prove to be important.

\section{Mechanism for the maintenance of the upper tropospheric warm anomaly}

The first law of thermodynamics used in this study is expressed by

$$
\frac{\partial T}{\partial t}+V \cdot \nabla T=-\omega\left(\frac{\partial T}{\partial p}-\frac{R T}{c_{p} p}\right)+\frac{a\left(T_{c}-T\right)}{\Delta t},
$$

where the first term on the right represents adiabatic warming or cooling, and the second gives a measure of the cumulus-scale warming; $a$ represents the fraction 
TABLE 1. Parameters along backward trajectory passing through mid-level cyclone (Indochina).

\begin{tabular}{|c|c|c|c|c|c|c|c|c|c|c|c|c|}
\hline \multirow[b]{2}{*}{ Rows } & \multirow[b]{2}{*}{ Parameters } & \multicolumn{11}{|c|}{ Columns } \\
\hline & & 1 & 2 & 3 & 4 & 5 & $\begin{array}{l}6 \\
\downarrow\end{array}$ & $\stackrel{7}{7}$ Mid-level & $\stackrel{8}{\text { cyclone* }}$ & $\begin{array}{l}9 \\
\downarrow\end{array}$ & 10 & 11 \\
\hline 1 & $\begin{array}{l}\text { Time in hours along backward } \\
\text { trajectory }\end{array}$ & 0 & -4 & -8 & -12 & -16 & -20 & -24 & -28 & -32 & -36 & -40 \\
\hline 2 & $\begin{array}{l}\text { Observed temperature at } 500 \\
\mathrm{mb}\left({ }^{\circ} \mathrm{A}\right)\end{array}$ & 266.0 & 266.1 & 266.3 & 266.8 & 267.2 & 268.6 & 268.9 & 269.0 & 268.7 & 267.9 & 267.4 \\
\hline 3 & $\begin{array}{l}\text { Static stability } \sigma\left[\left(^{\circ} \mathrm{C}\right)\right. \\
\left.\sec ^{-1} \mathrm{mb}^{-1}\right]\end{array}$ & 0.071 & 0.074 & 0.078 & 0.073 & 0.069 & 0.065 & 0.065 & 0.061 & 0.062 & 0.064 & 0.065 \\
\hline 4 & $\begin{array}{l}\text { Calculated vertical velocity } \omega \\
\quad\left(10^{-5} \mathrm{mb} \mathrm{sec}^{-1}\right)\end{array}$ & 82 & 67 & 48 & 33 & 27 & 12 & 5 & 2 & -19 & -38 & -49 \\
\hline 5 & $\begin{array}{l}\text { Calculated temperature using } \\
\left.\text { adiabatic motions only ( }{ }^{\circ} \mathrm{A}\right)\end{array}$ & 266.0 & 266.2 & 267.0 & 267.5 & 267.7 & 267.8 & 267.9 & 267.9 & 267.8 & 267.6 & 267.4 \\
\hline 6 & $\begin{array}{l}\text { Calculated percent area } \\
\text { covered by convective } \\
\text { clouds }\end{array}$ & 0 & 0 & 0 & 0 & 0.4 & 1.2 & 1.8 & 1.9 & 0.6 & 0 & 0 \\
\hline 7 & $\begin{array}{l}\text { Temperature difference } T_{c} \\
\text { between cloud and tropical } \\
\text { environment } T\left({ }^{\circ} \mathrm{A}\right)\end{array}$ & 0 & 0 & 0 & 0 & 3.4 & 3.1 & 3.3 & 3.6 & 3.1 & 0 & \\
\hline 8 & $\begin{array}{l}\text { Diabatic warming by cumulus } \\
\text { scale }\left[\left({ }^{\circ} \mathrm{A}\right)(4 \mathrm{hr})^{-1}\right]\end{array}$ & 0 & 0 & 0 & 0 & 0.21 & 0.58 & 0.95 & 1.12 & 0.29 & 0 & 0 \\
\hline 9 & $\begin{array}{l}\text { Estimated longwave radiative } \\
\text { warming }\left[\left({ }^{\circ} \mathrm{A}\right)(4 \mathrm{hr})^{-1}\right]\end{array}$ & - & -0.2 & -0.2 & -0.2 & -0.2 & -0.2 & -0.2 & -0.2 & -0.2 & -0.2 & -0.2 \\
\hline 10 & $\begin{array}{l}\text { Net calculated temperature } \\
\text { along trajectory }\left({ }^{\circ} \mathrm{A}\right)\end{array}$ & 266.0 & 266.5 & 267.0 & 267.3 & 267.7 & 268.2 & 268.7 & 268.8 & 267.9 & 267,4 & 267.2 \\
\hline
\end{tabular}

* Arrows indicate general location of mid-level cyclones.

of the synoptic scale area covered by convective elements; and $\Delta t$ is a cloud time scale. We also note that

$$
\sigma=-\left(\frac{\partial T}{\partial p}-\frac{R}{c_{p} P} T\right)
$$

a measure of static stability, is positive on the synoptic scale.

The warm anomaly above the mid-level cyclone could be maintained by subsidence warming. Several backward trajectories were constructed in order to assess the contribution of this effect. It soon became obvious that large-scale descending motions alone could not account for the observed warm anomalies, e.g., $\sigma$ is of the order of $0.07 \mathrm{C} \mathrm{mb}^{-1}$, while $\omega$ is of the order of $30 \times 10^{-5} \mathrm{mb} \mathrm{sec}^{-1}$.

The order of magnitude of the cumulus-scale warming can be obtained by assuming $a=0.01, T_{c}-T \sim 3 \mathrm{C}$ and $\Delta t \sim 15 \mathrm{~min}$. The orders of magnitude of the two terms are therefore

$$
\begin{aligned}
& \sigma \omega \sim 2.1 \times 10^{-5} \mathrm{C} \mathrm{sec}^{-1}, \\
& \frac{a(T c-T)}{\Delta t} \sim 3.3 \times 10^{-5} \mathrm{C} \mathrm{sec}^{-1} .
\end{aligned}
$$

\begin{tabular}{|c|c|c|c|c|c|c|c|c|c|c|c|c|}
\hline Rows & Parameters & 1 & 2 & 3 & 4 & 5 & $\begin{array}{c}\text { Colum } \\
6\end{array}$ & $\begin{array}{l}7 \\
\downarrow\end{array}$ & $\stackrel{8}{\text { Mid-level }}$ & $\stackrel{9}{9}$ cyclone* $^{*}$ & $\begin{array}{l}10 \\
\downarrow\end{array}$ & 11 \\
\hline 1 & $\begin{array}{l}\text { Time in hours along back- } \\
\text { ward trajectory }\end{array}$ & 0 & -4 & -8 & -12 & -16 & -20 & -24 & -28 & -32 & -36 & -40 \\
\hline 2 & $\begin{array}{l}\text { Observed temperature at } \\
500 \mathrm{mb}\left({ }^{\circ} \mathrm{A}\right)\end{array}$ & 265.1 & 266.0 & 266.7 & 267.2 & 267.8 & 268.7 & 269.3 & 268.8 & 268.2 & 267.0 & 266.1 \\
\hline 3 & $\begin{array}{l}\text { Static stability } \sigma\left[\left({ }^{\circ} \mathrm{C}\right)\right. \\
\left.\sec ^{-1} \mathrm{mb}^{-1}\right]\end{array}$ & 0.077 & 0.079 & 0.085 & 0,089 & 0.089 & 0.083 & 0.081 & 0.082 & 0.077 & 0.073 & 0.073 \\
\hline 4 & $\begin{array}{l}\text { Calculated vertical velocity } \\
\omega\left(10^{-5} \mathrm{mb} \mathrm{sec}^{-1}\right)\end{array}$ & 40 & 43 & 56 & 44 & 32 & 28 & -27 & -51 & -85 & -106 & -58 \\
\hline 5 & $\begin{array}{l}\text { Calculated temperature using } \\
\text { adiabatic motions } \\
\left.\text { only ( }{ }^{\circ} \mathrm{A}\right)\end{array}$ & 265.1 & 265.6 & 266.3 & 266.9 & 267.3 & 267.7 & 267.4 & 266.8 & 265.9 & 264.8 & 264.2 \\
\hline 6 & $\begin{array}{l}\text { Calculated percent area } \\
\text { covered by convective } \\
\text { clouds }\end{array}$ & 0 & 0 & 0 & 0 & 0.3 & 1.1 & 1.7 & 1.6 & 0.9 & 0.5 & 0.1 \\
\hline 7 & $\begin{array}{l}\text { Temperature difference } T_{\varepsilon} \\
\text { between cloud and tropical } \\
\text { environment } T\left({ }^{\circ} \mathrm{A}\right)\end{array}$ & 0 & 0 & 0 & 0 & 3.7 & 3.8 & 4.1 & 4.0 & 3.3 & 3.6 & 3.5 \\
\hline 8 & $\begin{array}{l}\text { Diabatic warming by cu- } \\
\text { mulus scale }\left[\left({ }^{\circ} \mathrm{A}\right)(4 \mathrm{hr})^{-1}\right]\end{array}$ & 0 & 0 & 0 & 0 & 0.18 & 0.67 & 1.12 & 1.02 & 0.48 & 0.29 & 0.06 \\
\hline 9 & $\begin{array}{l}\text { Estimated longwave radiative } \\
\text { warming }\left[\left(\left(^{\circ} \mathrm{A}\right)(4 \mathrm{hr})^{-1}\right]\right.\end{array}$ & - & -0.20 & -0.20 & -0.20 & -0.20 & -0.20 & -0.20 & -0.20 & -0.20 & -0.20 & -0.20 \\
\hline 10 & $\begin{array}{l}\text { Net calculated temperature } \\
\text { along trajectory }\left({ }^{\circ} \mathrm{A}\right)\end{array}$ & 265.1 & 265.4 & 266.1 & 266.7 & 267.3 & 268.2 & 268.3 & 267.6 & 266.2 & 264.9 & 264.1 \\
\hline
\end{tabular}

Over a period of $24 \mathrm{hr}$, parcels moving through this

TABLE 2. Parameters along backward trajectory passing through mid-level cyclone (India).

* Arrows indicate general location of mid-level cyclone. 
TABLE 3. Time variation of $T_{C}-T\left({ }^{\circ} \mathrm{C}\right)$ at selected stations in the vicinity of mid-level cyclone, for various days in June 1966 at 1200 GMT.

\begin{tabular}{|c|c|c|c|c|c|c|c|c|c|c|}
\hline \multirow[b]{2}{*}{ Pressure } & \multicolumn{10}{|c|}{ Date } \\
\hline & 9 & 10 & 11 & 12 & 13 & 14 & 15 & 16 & 17 & 18 \\
\hline \multicolumn{11}{|l|}{ Saigon } \\
\hline $\begin{array}{l}850 \\
700 \\
500 \\
400 \\
300 \\
200\end{array}$ & $\begin{array}{r}1.7 \\
4.4 \\
1.9 \\
0.9 \\
1.0 \\
-4.4\end{array}$ & $\begin{array}{r}2.3 \\
3.1 \\
2.5 \\
1.5 \\
0.6 \\
-5.2\end{array}$ & $\begin{array}{r}3.0 \\
3.2 \\
-0.2 \\
0.1 \\
0.6 \\
-4.7\end{array}$ & $\begin{array}{r}5.3 \\
3.1 \\
0.6 \\
1.5 \\
0.5 \\
-0.3\end{array}$ & $\begin{array}{c}3.0 \\
1.7 \\
3.9 \\
1.8 \\
0 \\
-5.1\end{array}$ & $\begin{array}{r}1.1 \\
1.2 \\
2.4 \\
1.0 \\
-0.2 \\
-5.0\end{array}$ & $\begin{array}{r}2.3 \\
0.7 \\
2.2 \\
1.0 \\
-0.9 \\
-4.2\end{array}$ & $\begin{array}{r}3.0 \\
1.7 \\
0.8 \\
1.2 \\
-0.4 \\
-4.9\end{array}$ & $\begin{array}{c}2.4 \\
1.7 \\
0.6 \\
1.2 \\
0 \\
-5.1\end{array}$ & $\begin{array}{c}1.4 \\
1.0 \\
1.7 \\
0 \\
-0.8 \\
-0.4\end{array}$ \\
\hline \multicolumn{11}{|l|}{ Bangkok } \\
\hline $\begin{array}{l}850 \\
700 \\
500 \\
400 \\
300 \\
200\end{array}$ & $\begin{array}{c}3.1 \\
4.8 \\
0.8 \\
0 \\
-0.0 \\
-5.3\end{array}$ & $\begin{array}{r}9.3 \\
4.6 \\
4.4 \\
1.2 \\
-0.2 \\
-4.2\end{array}$ & $\begin{array}{r}7.5 \\
2.7 \\
2.9 \\
1.2 \\
0.2 \\
-5.2\end{array}$ & $\begin{array}{r}5.3 \\
2.3 \\
3.0 \\
1.7 \\
0.2 \\
-4.5\end{array}$ & $\begin{array}{r}1.2 \\
1.8 \\
1.6 \\
1.9 \\
0.3 \\
-5.2\end{array}$ & $\begin{array}{r}2.4 \\
1.8 \\
2.9 \\
2.2 \\
0.4 \\
-5.0\end{array}$ & $\begin{array}{l}2.4 \\
1.8 \\
0.9 \\
2.2 \\
0.1 \\
-\end{array}$ & $\begin{array}{r}3.5 \\
3.5 \\
3.2 \\
2.0 \\
1.4 \\
-4.9\end{array}$ & $\begin{array}{r}3.1 \\
2.3 \\
2.2 \\
1.3 \\
-0.2 \\
-5.2\end{array}$ & $\begin{array}{r}2.2 \\
3.1 \\
1.9 \\
1.1 \\
0.3 \\
-4.9\end{array}$ \\
\hline
\end{tabular}

region would experience a warming of the order of 3-4C. Both of these mechanisms are important.

Tables 1 and 2 show the distribution of selected computed parameters along backward trajectories based on our solutions of the balanced mode. The tables, respectively, are for trajectories passing through the mid-level cyclone over southern Indochina and over the Arabian Sea. These detailed computations confirm our order of magnitude estimates discussed above. The estimates of net radiative cooling in row 9 are taken to be $1.2 \mathrm{C} \mathrm{day}^{-1}$, based on values given by London (1957). It may be noted that the location of the center of the mid-level cyclone is close to column 8 in each table.

Table 3 shows values of $\left(T_{c}-T\right)$ based on conservation of equivalent potential temperature (i.e., parcel ascent) for Saigon and Bangkok for a 10-day period at $1200 \mathrm{GCT}$ during June 1966 . The temperatures $T_{c}$ of the parcel are greater than $T$ below $300 \mathrm{mb}$. Values of $\left(T_{c}-T\right)$ over the troposphere, which refer to conditions near sunset, are as large as 5-6C, and under favorable conditions can produce significant warming of the air at upper levels on a synoptic scale. Conditions during the day would lead to even larger values of $\left(T_{c}-T\right)$. The present investigation deals with diagnostic calculations of the three-dimensional motion field. Such studies have obvious disadvantages in that only limited conclusions can be drawn regarding the importance of various mechanisms. The manner by which adiabatic warming and cumulus-scale heating couple to produce isolated warm anomalies can only be examined by a prediction experiment. Since these mid-level disturbances are present in the monthly-averaged maps, the role of orography, warm continents, and air-sea interaction must be important. These features must be included for a successful simulation of the phenomenon.

Murakami et al. (1969) have made a remarkable start on a two-dimensional formulation of a zonally symmetric monsoon problem. They have produced a reasonably successful simulation of the mean zonal circulation of the Asian summer monsoon by incorporating various features such as eddy diffusion of momentum, heat and water vapor in the boundary layer. They perform a detailed computation of the heat balance of the earth's surface to predict its surface temperature. Cumulus convection is parameterized by a procedure similar to that of Manabe and Smagorinsky (1967). This simulation of the zonally symmetric summer monsoon does not contain any evidence of the mid-level cyclonic vorticity maxima at 20 or at $10 \mathrm{~N}$. This, of course, should not be expected because of the symmetry restriction and the scale of this phenomenon. We feel that investigations of mid-level cyclones will be an interesting asymmetric problem of the monsoon circulation. A soultion of this could be accomplished by extension of numerical models of the type formulated by Murakami and his collaborators and relaxing the symmetry constraints. Alternatively, one might wish to explain the "trapped" mid-level vorticity maxima as a dynamic instability problem in the presence of horizontal and vertical shear flows.

During the summer season in the middle latitudes, zonal winds change from westerlies in the troposphere to easterlies in the stratosphere. Charney and Drazin (1961) have shown that such a vertical distribution of zonal currents inhibits a vertical propagation of energy of long quasi-geostrophic waves. There is a close analogy to such a phenomenon in the tropical troposphere over the region of the southwest monsoons. Over southeast Asia, a strong belt of surface westerlies decreases with height and above $500 \mathrm{mb}$ easterlies are found with an easterly jet around $150 \mathrm{mb}$. We might speculate that a critical level exists around $500 \mathrm{mb}$ such that synoptic-scale energy at lower levels is trapped below or around the critical level. This trapping might manifest itself in the form of large mid-tropospheric eddy kinetic energy in these mid-level cyclones. There 
is an important difference between the monsoon situation and the larger scale waves considered by Charney and Drazin. This is due to the deep cumulus convection which transfers large amounts of energy to very high levels from the boundary layers of the southwest monsoon. This energy is linked to motions on the mesoscale in the boundary layer, because of the more direct association of cumulus convection with mesoscale motions rather than with the larger synoptic-scale motion. This analogy appears worth examining in greater detail.

\section{Energy transformations by cumulus- and synoptic-scale motions}

If calculations of energetics are to be carried out over the entire globe, a simple formulation of the energy transformation equations can be obtained. In such a problem the generation of eddy kinetic energy can be related to internal barotropic and baroclinic exchanges. On the other hand, when open boundaries are considered, large non-vanishing boundary fluxes are usually present and a simple interpretation of the energetics of the system is generally not possible. The structure of the mid-level cyclones has been obtained by solving the balance equation over a limited portion of the globe. The results of these computations of energetics are more in the line of so-called budget studies.

\section{a. Energy equations}

The local change of kinetic energy, per unit mass of air, can be written as

$$
\begin{array}{r}
\frac{\partial K}{\partial t}=-\nabla \cdot[(K+\phi) V]-\frac{\partial}{\partial p}[(K+\phi) \omega] \\
-\frac{R T}{p} \omega-\mathbf{V} \cdot \mathbf{F} .
\end{array}
$$

Upon integration over a mass $m$ of the atmosphere, this may be written as

$$
\begin{aligned}
& \frac{\partial \bar{K}}{\partial t}=-\frac{1}{g} \int_{p} \int_{S}(K+\phi) C_{n} d S d p \\
&-\frac{1}{g} \int_{p} \int_{y} \int_{x}(\omega \alpha) d x d y d p \\
& \quad-\frac{1}{g} \int_{p} \int_{y} \int_{x}(\mathbf{V} \cdot \mathbf{F}) d x d y d p,
\end{aligned}
$$

where $C_{n}$ is an outward normal velocity in the horizontal direction; $\bar{K}$, the total kinetic energy, is then given by

$$
\bar{K}=\int_{m} K d m=\frac{1}{g} \int_{p} \int_{y} \int_{x} K d x d y d p .
$$

Vertical motion is assumed to be zero at $100 \mathrm{mb}$ in the balanced model used in this study. The contribution to the energetics due to vertical advections at $1000 \mathrm{mb}$ have been neglected. Frictional dissipation of kinetic energy is expressed in terms of the surface drag (drag coefficient $C_{D}=1.0 \times 10^{-3}$ ) and is roughly proportional to the cube of the surface wind speed.

\section{b. Parameterization of cumulus convection}

In tropical energetics the contribution to the $\omega \alpha$ correlation arises partly from larger scale and partly from the cumulus-scale motions. It is possible to obtain a measure of the vertical motion that is relevant to the cumulus scale by the following procedure.

The net convergence of flux of moisture into a unit vertical column extending from the top of the friction layer to the top of the atmosphere may be expressed by

$$
I=-\frac{\omega_{f} q_{f}}{g}\left[\mathrm{mb} \mathrm{m}^{-1} \mathrm{sec}^{-1}\right]
$$

where the subscript $f$ refers to the top of the friction layer. For large-scale motions $I$ is roughly $10^{-6}$ units in the tropics (Krishnamurti, 1968b). Following Kuo, we form a model cloud which requires a net convergence of flux of moisture to replace the tropical sounding $(T, q)$ by a moist adiabat $\left(T_{c}, q_{c}\right)$. At any level this may be expressed by

$$
-\frac{\partial}{\partial p} \omega_{c} q_{c}=C_{p} \frac{\left(T_{c}-T\right)}{L \Delta t}+\frac{\left(q_{c}-q\right)}{\Delta t},
$$

where $\Delta t$ is a cloud time scale. Along an undilute cloud element, $\partial \omega_{c} / \partial p=0$, since no entrainment is assumed. We may thus approximate $\omega_{c}$ by

$$
\omega_{c}=-\left[\frac{C_{p}\left(T_{c}-T\right)}{L}+\left(q_{c}-q\right)\right] /\left[\frac{\partial q_{c}}{\partial p} \Delta t\right] .
$$

This expression for the vertical velocity of cumulus-scale motion is such that $\omega_{c}$ will be zero at the lifting condensation level and at the level where the tropical sounding intersects the moist adiabat. In between these levels there would be rising motion because $T_{c}-T, q_{c}-q$ and $\partial q_{c} / \partial p$ are all positive. A typical magnitude of $\omega_{c}$ at $500 \mathrm{mb}$ is roughly $10^{-1} \mathrm{mb} \mathrm{sec}^{-1}\left(=1 \mathrm{~m} \mathrm{sec}^{-1}\right)$. The maximum amount of moisture convergence required to produce the model cloud over a synoptic-scale unit area is expressed by

$$
Q=-\frac{1}{g} \int_{p_{B}}^{p}{ }_{T}\left[\frac{C_{p}\left(T_{c}-T\right)}{L \Delta t}+\frac{q_{c}-q}{\Delta t}\right] d p,
$$

the units of $Q$ being the same as those of $I$. In a conditionally unstable tropical atmosphere $Q \sim 10^{-4}$ units. Since $I$ is the available moisture convergence, the ratio

$$
a=I / Q
$$


may be regarded as a fraction of the synoptic-scale unit area covered by convective model clouds.

There are several limitations in the parameterization procedure and the numerical procedures used for evaluation of the three-dimensional motion field; these are discussed at some length in Krishnamurti (1968a, b).

\section{c. Energy releases by convective-scale motions}

A measure of the contribution to the $\omega \alpha$ correlation by the convective scale can be obtained by the integral

$$
-\frac{R}{g} \int_{p} \int_{y} \int_{x}\left[\frac{a \omega_{c}\left(T_{c}-T\right)}{p}\right] d x d y d p
$$

The horizontal distribution of $a$ is taken into account here, all clouds in each synoptic unit area being alike but differing from one region to another.

\section{d. Energy releases by synoptic-scale motion}

Using the synoptic-scale vertical motions discussed earlier in this paper, a contribution to $\omega \alpha$ by this scale may be expressed by

$$
-\frac{R}{g} \int_{p} \int_{y} \int_{x}\left[\frac{\left(\bar{\omega} \bar{T}+\bar{\omega}^{\prime} \bar{T}^{\prime}\right)}{p}\right] d x d y d p
$$

where we assume that $a \ll 1$ and $1-a \sim 1$.

It is easy to obtain a rough comparison of the contribution by the two scales within the framework of the parameterization procedure followed here. In an active convective disturbance like the mid-level cyclone

$$
\left.\begin{array}{rl}
\omega_{c} & =10^{-1} \mathrm{mb} \mathrm{sec}^{-1} \\
\omega^{\prime} & =10^{-3} \mathrm{mb} \mathrm{sec}^{-1} \\
T_{c}-T & =4 \mathrm{C} \\
T^{\prime} & =4 \mathrm{C} \\
a & =1 \%
\end{array}\right\},
$$

and we note that $a \omega_{c}\left(T_{c}-T\right)=\omega^{\prime} T^{\prime}$. This suggests that over active convective regions the contributions by the two scales may be comparable.

\section{e. Resulls of energy computations}

We have evaluated the various integrals of the kinetic energy equation for the four map times of Fig. 4. A box with sides along $7 \mathrm{~N}, 19 \mathrm{~N}, 95 \mathrm{E}$ and $115 \mathrm{E}$ encloses the mid-level cyclone in each case.

The following is a summary of the results of computations :

Convergence of flux of potential and kinetic energy into box

$$
-12.8 \times 10^{18} \mathrm{ergs} \mathrm{sec}^{-1}
$$

Dissipation of kinetic energy by surface friction

$$
4.11 \times 10^{18} \mathrm{ergs} \mathrm{sec}^{-1}
$$

Generation of kinetic energy by $\left(\omega^{\prime} \alpha^{\prime}\right)$ synoptic scale

$$
-24.7 \times 10^{18} \mathrm{ergs} \mathrm{sec}^{-1}
$$

Generation of kinetic energy by $\left(\omega^{\prime} \alpha^{\prime}\right)$ cumulus scale

$$
39.2 \times 10^{18} \mathrm{ergs} \mathrm{sec}^{-1}
$$

\section{Net imbalance}

$$
-2.3 \times 10^{18} \text { ergs sec}^{-1} \text {. }
$$

This imbalance is due to such factors as 1) contribution by $\bar{\omega} \bar{\alpha}$ which would depend on the size of the box, 2) local changes of kinetic energy in the box, and 3) truncation errors in the estimates and in the averaging processes. For the present we shall not be concerned with an explanation of these imbalances because of the approximations and sources of error in such computations. We find that the synoptic-scale $\left(\omega^{\prime} \alpha^{\prime}\right)$ contribution transforms eddy kinetic into eddy potential energy. As stated earlier this became obvious when we examined the maps of synoptic-scale vertical motions and temperatures. We found that the centers of maximum sinking motions were located closer to the centers of warm anomalies. The important role of the cumulus scale on the energetics becomes clearer from these computations. Part of the kinetic energy released by the cumulus-scale motions is exported out of the box and part of it cancels the synoptic-scale conversions. In the absence of the cumulus scale this system cannot be maintained in steady state, because the synoptic-scale energy/conversions, friction, and the exports would destroy its kinetic energy. It is also very interesting to compare the role of these two scales in maintaining the warm anomaly above the mid-level cyclone as well as energy conversions:

1) Both scales account for warming above the mid-level cyclone.

2) Cumulus-scale opposes the synoptic-scale energy conversion, the former being somezhat larger in magnitude.

We feel that further studies should be carried out to understand the coupling of these two scales of motions discussed in this paper. It would also be worthwhile to see if such a dual role is found in other tropical weather systems.

Acknowledgments. We would like to express our appreciation to Prof. C. L. Jordan for his comments on this work. Financial support for this work was received from the Atmospheric Science Section, National Science Foundation, under NSF Grant GA-1480 and Department of the Army THEMIS Contract No. DAAB 07-69-C-0062. Computing time was provided by the Florida State University Computing Center. 


\section{APPENDIX}

\section{List of Symbols}

$L \quad$ latent heat of vaporization of air

$B_{S}, H_{L} \quad$ sensible and latent heat (respectively) per unit mass of air

$C_{p} \quad$ specific heat of air at constant pressure

$a$ fraction (or per cent) of synoptic-scale area covered by convective clouds

$\theta_{e} \quad$ equivalent potential temperature

$R \quad$ gas constant

$T_{a} \quad$ temperature of air at anemometer level, same as $T_{1000}$ in this study

$T_{c} \quad$ temperature of air at cloud level

$T_{w} \quad$ temperature of water

$V \quad$ total wind speed

$g \quad$ acceleration of gravity

$\psi \quad$ streamfunction

$\zeta, \zeta_{a} \quad$ relative and absolute vorticity

$\nabla^{2} \quad \partial^{2} / \partial_{x}{ }^{2}+\partial^{2} / \partial_{y}{ }^{2}$

$\nabla \quad \partial / \partial_{x}+\partial / \partial_{y}$

$\chi \quad$ divergent part the wind field, a velocity potential

II $\quad$ Exner pressure, $R T /(p \theta)$

$\beta \quad$ the beta parameter, $\partial f / \partial_{y}$

$\sigma \quad$ static stability parameter,

$[(R T /-p \theta)(\partial \theta / \partial p)]$

$\omega \quad$ vertical velocity, $(d p / d t)$

$f \quad$ Coriolis parameter

$T_{S}, q_{S}$ temperature and specific humidity (respectively) of a parcel raised vertically above the 900-mb surface with no lateral mixing

$T, \theta \quad$ temperature and potential temperature of air (respectively)

$V_{\psi} \quad$ nondivergent part of the wind

$I$ net moisture convergence in a unit vertical column extending from $900 \mathrm{mb}$ to the top of the atmosphere $(100 \mathrm{mb})$

$x, y, p, t$ independent variables

$K \quad$ kinetic energy, $\left(u^{2}+v^{2}\right) / 2$

$\phi \quad$ potential energy, $g z$

$\alpha \quad$ specific volume

$q \quad$ specific humidity

$h \quad$ terrain height above sea level

$\mathbf{i}, \mathbf{j}, \mathbf{k}$ unit vectors along zonal, meridional and vertical directions

$\tau_{x}, \tau_{y} \quad$ frictional stresses along $x$ and $y$ directions $\begin{array}{ll}\text { F } & \text { frictional force } \\ \text { V } & \text { horizontal wind vector }\end{array}$

\section{REFERENCES}

Bunker, A. F., 1965 : Interaction of the summer monsoon air with the Arabian Sea. Proc. Symp. Meleorological Results of the Intern. Indian Ocean Expedition, WMO, Geneva, 3-16.

Charney, J. G., 1968: The intertropical convergence zone and the Hadley circulation of the atmosphere. Proc. Conf. Numerical Weather Prediction, III 73-III, Japan Meteor. Agency, 79 pp.

- 1969: A further note on large scale motions in the tropics. J. Atmos. Sci., 26, 182-185.

- , and P. G. Drazin, 1961: Propagation of planetary-scale disturbances from the lower into the upper atmosphere. J. Geophys. Res., 66, 83-110.

Erickson, C., 1969: Diagnostic study of an upper cold low (Abstract). Trans. Amer. Geophys. Union, 50, 179.

Fujita, T. T., K. Watanabe and T. Izawa, 1969: Formation and structure of equatorial anticyclones caused by large scale equatorial flows. J. Appl. Meteor., 8, 649-667.

Hawkins, H. E., and S. L. Rosenthal, 1965: On the computation of the streamfunction from the wind field. Mon.Wea. Rev., 93, 245-252.

Kreitzberg, C. W., 1969: Mesoscale and diurnal variations deduced from the Saigon areas rawinsonde data. Proc. Conf. Summer Monsoon of Southeast Asia, University of Hawaii (in press).

Krishnamurti, T. N., 1968a: A diagnostic balance model for studies of weather systems of low and high latitude, Rossby number less than 1. Mon. Wea. Rev., 96, 197-207.

$\ldots, 1968 \mathrm{~b}$ : A calculation of the per cent area covered by convective clouds from moisture convergence. J. Appl. Meteor., 7, 184-195.

Kuo, H. L. 1965: On formation and intensification of tropical cyclones through latent heat release by cumulus convection. J. Atmos. Sci., 22, 40-63.

London, J., 1957: A study of atmospheric heat balance. Final Rept. 1-67 to Air Force Cambridge Research Labs., Dept. of Meteor., New York University.

Manabe, S., and J. Smagorinsky, 1967 : Simula ted climatology of a general circulation model with a hydrologic cycle II: Analysis of the tropical atmosphere. Mon. Wea. Rev., 95, 155-169.

Miller, F. R., and R. N. Keshavamurthy, 1967: Structure of an Arabian Sea Summer Monsoon System. Honolulu, East-West Center Press, 1-94.

Murakami, T., R. V. Godbole and R. R. Kelkar, 1969: Numerical simulation of the monsoon along $80^{\circ} \mathrm{E}$. Proc. Conf. Summer Monsoon of Southeast Asia, University of Hawaii (in press).

Normand, C. W. B., 1943: Climatological Atlas for Airmen. Poona, India, Yeravda Prison Press, 1-101.

Riehl, H., 1954: Tropical Meleorology. New York, McGraw-Hill, $392 \mathrm{pp}$.

Sadler, J. C., 1968: Forecasting minimum cloudiness over the Red River Delta during the summer monsoon. Final Rept., Contract AFCRL-68-481, University of Hawaii, 104 pp.

Yanai, M., et al., 1968: Power spectra of large scale disturbances over the tropical Pacific. J. Meteor. Soc. Japan, 46, 801-816. 